\title{
Chromosome Painting in Lonchorhina aurita Sheds Light onto the Controversial Phylogenetic Position of Sword-Nosed Bats (Chiroptera, Phyllostomidae)
}

\author{
João C. Farias ${ }^{\mathrm{a}}$ Neide Santos ${ }^{\mathrm{a}}$ Darlene P. Bezerra ${ }^{\mathrm{a}} \quad$ Cibele G. Sotero-Caio $^{\mathrm{a}}{ }^{\mathrm{b}}$ \\ aDepartamento de Genética, Centro de Biociências, UFPE- Universidade Federal de Pernambuco, Recife, Brazil; \\ bWellcome Sanger Institute, Wellcome Genome Campus, Hinxton, Cambridgeshire, United Kingdom
}

\section{Keywords}

FISH · Karyotype evolution · Lonchorhininae .

Phyllostomidae

\begin{abstract}
The subfamily Lonchorhininae encompasses 6 species of sword-nosed bats (Lonchorhina) and is one of the most problematic lineages in the Neotropical leaf-nosed bats (Phyllostomidae) phylogeny. There are at least 5 different hypotheses to explain when the subfamily diverged from the remaining phyllostomids, but none with robust statistical support. Here, we generated a chromosome painting homology map of Lonchorhina aurita karyotype $(2 n=32$ and $F N=60)$ using whole-chromosome probes of Macrotus californicus (MCA; $2 \mathrm{n}=40$ and $\mathrm{FN}=60$ ). We placed the karyotype changes of $L$. aurita in a phylogenetic context to discuss the most likely branching position of Lonchorhininae based on karyotypic evolution. We show that $L$. aurita has a derived karyotype with 24 segments homologous to the 20 MCA chromosomes used as probes. Comparative analyses between 7 published painted bats species across 4 phyllostomid subfamilies (Macrotinae, Phyllostominae, Glossophaginae, and Lonchophyllinae) revealed that one inversion (MCA 4inv) and one fusion (MCA $17+18)$ are shared derived features between the karyotypes of $L$. aurita and species of Phyllostominae not yet
\end{abstract}

observed in other bats. Our data show that chromosomal homology maps may contribute with new insights into a long-standing phylogenetic debate that has endured for decades.

(c) 2022 S. Karger AG, Basel

\section{Introduction}

The insectivorous sword-nosed bats of the genus Lonchorhina Tomes, 1863 are currently classified into 6 species (L. aurita, L. fernandezi, L. inusitata, L. mankomara, $L$. marinkellei, and $L$. orinocensis), characterized by the largest nose leaves in the Neotropical family Phyllostomidae [Mantilla-Meluk et al., 2019; Simmons and Cirranello, 2020]. Morphological data traditionally placed Lonchorhina within the subfamily Phyllostominae [Wetterer et al., 2000], but earlier molecular phylogenies supported the recognition of a new monotypic subfamily, Lonchorhininae [Baker et al., 2003a]. In this classification, based on mtDNA and nuclear RAG2 sequence data, Lonchorhininae appears as a basal branch relative to Phyllostominae that diverged after Macrotinae, Micronycterinae, and Desmodontinae. Thenceforth, studies based on larger molecular datasets and different methods have displayed alternative branching positions for Lon-

karger@karger.com

(c) 2022 S. Karger AG, Basel

www.karger.com/cgr

Karger ${ }^{\prime \prime}=$
Correspondence to:

João C. Farias, cfarias.joao@gmail.com 
Table 1. Summary of syntenic associations and conserved chromosomes of Macrotus californicus (MCA) detected by chromosome painting in Phyllostomidae

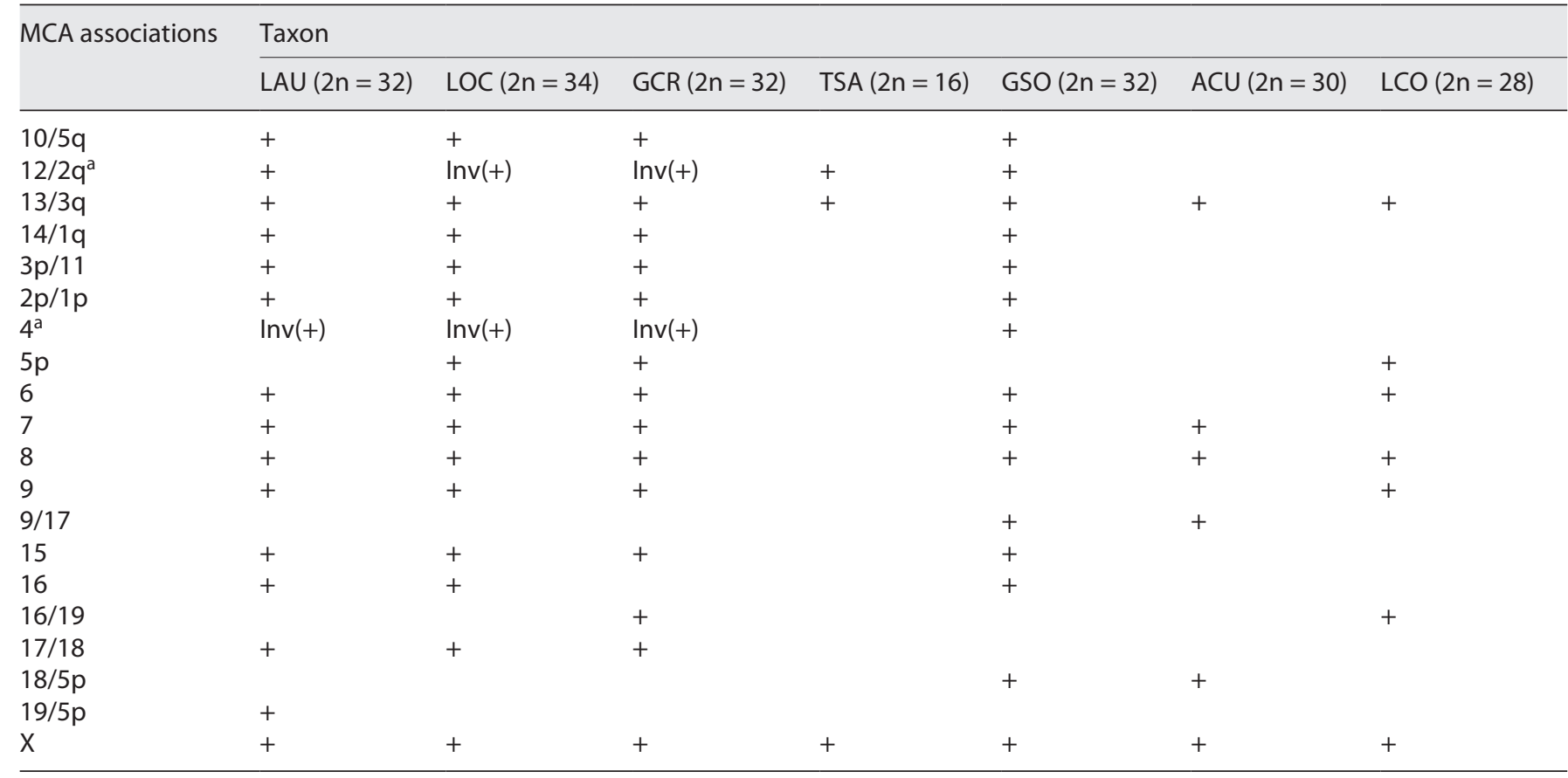

The abbreviations represent taxa analyzed sensu Baker et al. [2016]. Lonchorhininae: LAU, Lonchorhina aurita - data from the present report. Phyllostominae: LOC, Lophostoma occidentali; GCR, Gardnerycteris crenulatum; TSA, Tonatia saurophila - data from Sotero-Caio et al., [2015]. Glossophaginae: GSO, Glossophaga soricina; ACU, Anoura cultrata. Lonchophyllinae: LCO, Lonchophylla concava - data from Sotero-Caio et al. [2013]. ${ }^{a}$ Additional rearrangement distinguishes karyotypes by inversion (inv) of MCA, $12 \mathrm{inv}+2 \mathrm{q}$ and MCA, 4 inv, both submetacentric chromosomes.

chorhininae, but so far, no consensus has been reached and the phylogenetic position of the subfamily remains unclear [Rojas et al., 2011, 2016; Dumont et al., 2012; Dávalos et al., 2014; Baker et al., 2016; Amador et al., 2018].

In groups with such complex taxonomy and systematic issues, comparative cytogenetic approaches can be used in an integrative framework to refine available hypotheses of evolutionary relationships, given that chromosomal changes act as mutational events, and extant karyotypes can be traced back to ancestral states, recapturing the evolutionary process [Rokas and Holland, 2000]. Chromosome painting was proven very useful in the discussion of cytotaxonomic issues and understanding evolutionary processes in mammals [Ferguson-Smith and Trifonov, 2007]. In bats, this technique has allowed refinement of karyotypic evolution hypotheses [SoteroCaio et al., 2017; Solari et al., 2019], taxa delimitation [Volleth et al., 2017], and validation of the use of chromosome rearrangements as phylogenetic markers [Volleth et al., 2002; Benathar et al., 2019].
Among the available chromosome-specific probes derived from bats, those from Macrotus californicus $(2 \mathrm{n}=$ $40, \mathrm{FN}=60$ ) have the benefit of representing a karyotype closest to the ancestral karyotype of Phyllostomidae ( $M$. waterhousii, $2 \mathrm{n}=46, \mathrm{FN}=60$ ), which allows for straightforward inference of ancestral versus derived states in chromosome evolution studies within the family [Baker and Bickham, 1980]. Up to now, the karyotypes of 6 phyllostomid species have been painted with $M$. californicus probes (Table 1) [Sotero-Caio et al., 2013, 2015].

Herein, we generated a genome-wide homology map between M. californicus and L. aurita using M. californicus chromosome-specific probes. Our goals were to identify shared syntenic associations among $L$. aurita and published chromosome painting data from species encompassing 3 phyllostomid subfamilies (Phyllostominae, Glossophaginae, and Lonchophyllinae), as well as plotting the identified chromosome changes in contrasting phylogenetic hypotheses of Phyllostomidae and to discuss the most parsimonious phylogenetic position of the subfamily Lonchorhininae. 
a

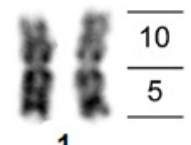

1

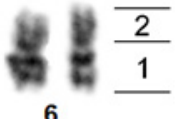

6
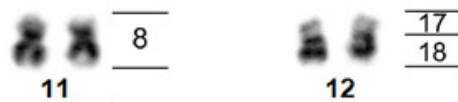

12
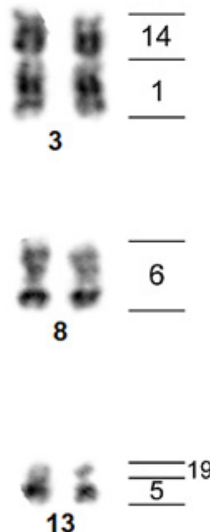
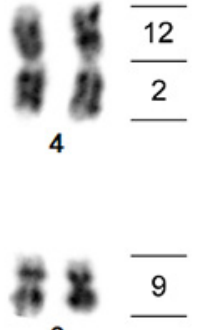

9

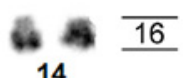

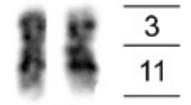

5
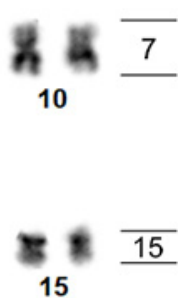
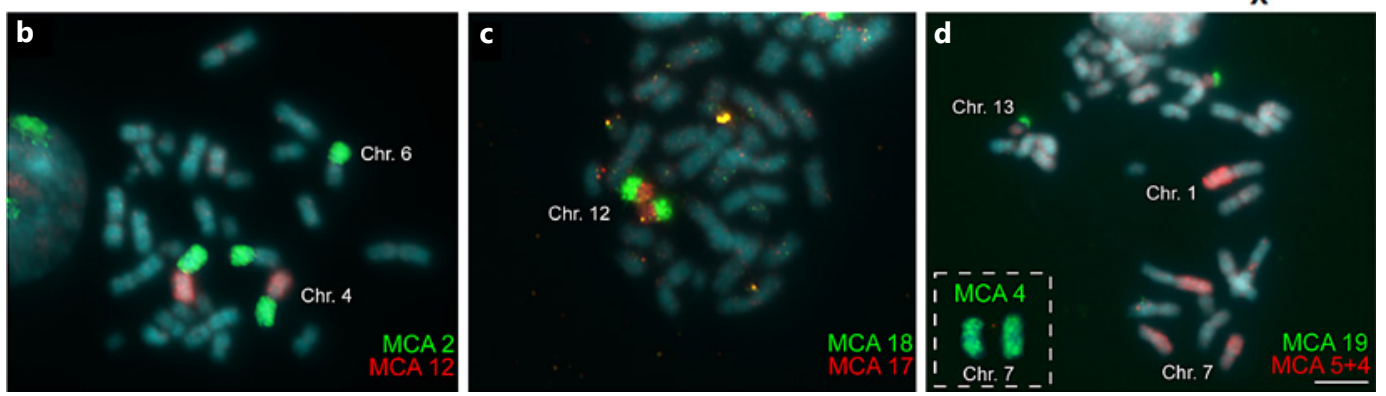

Fig. 1. Chromosome painting on Lonchorhina aurita (LAU) karyotype. a G-banding karyotype of a female LAU showing Macrotus californicus (MCA) chromosome homologies. b-d Mitotic metaphases showing examples of duo-color hybridizations of MCA probes. Biotin-labeled probes were detected with avidin-FITC (green) and digoxigenin-labeled probes with anti-digoxigenin-rhodamine (red). The slides were counterstained with DAPI. Scale bar, $5 \mu \mathrm{m}$.

\section{Materials and Methods}

\section{Sampling and Chromosome Banding}

Karyotype analyses were carried out in 4 L. aurita (LAU; 1 male and 3 females) collected in Toritama, Pernambuco, Brazil $\left(08^{\circ} 00^{\prime} 24^{\prime \prime}\right.$ $\mathrm{S}$ and $\left.36^{\circ} 03^{\prime} 24^{\prime \prime} \mathrm{W}\right)$. Voucher specimens were deposited in the mammalian collection at the Department of Zoology, Universidade Federal de Pernambuco, Brazil. Mitotic chromosomes were obtained from bone marrow following the standard protocol by Baker et al. [2003b] and G-banding was carried out in one reference female specimen following Seabright [1971] methods.

\section{Chromosome Painting and Comparative Analyses}

FISH was performed using whole-chromosome probes of the phyllostomid bat $M$. californicus (MCA; $2 \mathrm{n}=40$, XY; FN $=60$ ) prepared from flow-sorted chromosomes and DOP-PCR-labelled with biotin and digoxigenin [Sotero-Caio et al., 2013]. FISH was carried out on a female LAU sample as reference, following procedures previously described [Volleth et al., 2002; Sotero-Caio et al.,
2013]. The slides were denatured with $70 \%$ formamide $/ 30 \% 2 \times$ SSC at $75^{\circ} \mathrm{C}$ for $10 \mathrm{~min}$. No hybridization with MCA Y chromosome paint was performed. FISH images were captured using a Leica DMLB 5500B epifluorescence microscope and the Leica LasAF software and G-banding images using a Leica DM2500 and CytoVision 7.7 software. For image processing, brightness and contrast adjustments were performed using Adobe Photoshop CS5, and ideogram drawing was done on Inkscape (https://inkscape.org).

For comparative purposes, the chromosome painting data of the present study were integrated with those from Sotero-Caio et al. [2013, 2015], which used the same set of probes to 6 species of Phyllostomidae belonging to subfamilies Phyllostominae, Glossophaginae, and Lonchophyllinae (Table 1). Shared chromosome characters detected using MCA probes were parsimoniously plotted on respective ancestral nodes (across all taxonomic ranks) of phyllostomid phylogenetic trees. Under this method of comparative analysis, parsimony implies that when 2 or more species share a derived chromosome rearrangement, their most recent common 
ancestor also displayed that rearrangement. This approach was repeated for multiple phylogenetic hypotheses displaying alternative branching positions for the subfamily Lonchorhininae [Baker et al., 2003a, 2016; Rojas et al., 2011, 2016; Dávalos et al., 2014; Amador et al., 2018]. Finally, assessment of the number of events of chromosome rearrangements, as well as the number of required reversals to explain convergent events, allowed us to discuss when Lonchorhininae likely branched out during the radiation of phyllostomid bats according to karyotype evolution.

\section{Results}

All specimens of L. aurita (LAU) had a karyotype with $2 \mathrm{n}=32$ and a fundamental number of $\mathrm{FN}=60$ (Fig. 1a). Hybridization of $M$. californicus (MCA) chromosomespecific probes allowed us to provide a complete homology map of the L. aurita karyotype shown in Figure 1. FISH with the entire set of MCA autosomes + X chromo-

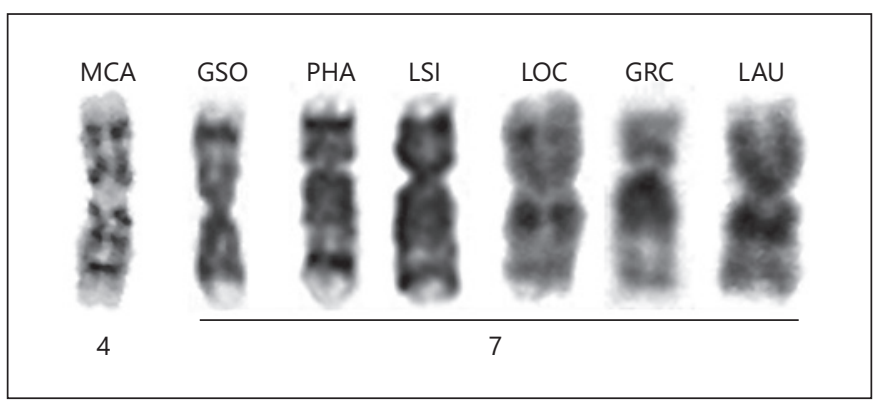

Fig. 2. G-banding comparison between Macrotus californicus (MCA) chromosome 4 and the correspondent syntenic homologies (pairs 7) in other phyllostomids: Glossophaga soricina (GSO; Glossophaginae); Phyllostominae: Lophostoma occidentalis (LOC), and Gardnerycteris crenulatum (GCR) modified from Sotero-Caio et al. [2013, 2015]; Phyllostomus hastatus (PHA) and Lophostoma silvicola (LSI) modified from Pieczarka et al. [2005] and Ribas et al. [2015]; and Lonchorhina aurita (LAU; Lonchorhininae).

Fig. 3. Integration of chromosome painting data to alternative phylogenetic hypotheses for Phyllostomidae subfamilies. Putative synapomorphies for subfamilies are mapped in slightly different nodes according to the Lonchorhininae position (red). a Hypothesis 1 tree recovered by Baker et al. [2003a] and hypothesis 2 by Rojas et al. [2011], Dumont et al. [2012], and Dávalos et al.[2014] (distinct only by branch order - dashed grey arrows). b Hypothesis 3 by Baker et al. [2016]. c Hypothesis 4 according to Rojas et al. [2016]. d Hypothesis 5 recovered by Amador et al. [2018]. The occurrence steps of derived characters MCA 4inv and $17+18$ are shown. e Ideograms indicate syntenic associations shared among lineages at the most basal family node (node A), also in the common ancestor of Lonchorhininae, Phyllostominae, Glossophaginae, and Loncho- some as probes identified a total of 24 homologous segments on the L. aurita genome (Fig. 1a). Eight L. aurita chromosomes (LAU 7, 8-11, 14, 15, and X) had hybridization signal conservation, with their whole chromosome length corresponding to single MCA chromosomes (MCA 4, 6-9, 15, 16, and X); however, LAU 7 differs from its homologous (MCA 4) by a pericentric inversion, which was confirmed by G-band comparison with other Phyllostomidae (Fig. 2). Four MCA probes revealed 2 distinct signals on different autosomes of L. aurita: MCA 1 (LAU 3 and 6), MCA 2 (LAU 4 and 6; Fig. 1b), MCA 3 (LAU 2 and 5), and MCA 5 (LAU 1 and 13; Fig. 1d). Most signals corresponded to entire chromosome arms; however, MCA 13 signal encompassed the entire short arm (LAU $2 \mathrm{p}$ ) and also the portion of the long arm (2q proximal) of the submetacentric LAU 2. In addition, 6 probes hybridized only to a single chromosome arm (MCA 11, 12, 14, 17, 18, and 19; Fig. 1b-d).

The comparative analysis showed several conserved chromosomes and syntenic associations in all phyllostomids analyzed (Table 1). Thirteen autosome associations were shared between L. aurita and species of the subfamily Phyllostominae, and 11 between L. aurita and Glossophaga soricina (GSO, Glossophaginae). Most of the conserved chromosome/chromosome associations were shared across investigated species and thus could be plotted at the most basal family node (node A; Fig. 3). Other conserved chromosomal associations were likely present in the common ancestor of Lonchorhininae, Phyllostominae, Glossophaginae, and Lonchophyllinae (node B; Fig. 3).

Interestingly, the L. aurita karyotype, but no other analyzed species, presents 2 derived syntenies in common with Phyllostominae (inversion [inv] MCA 4inv and $17+$ 18; Table 1, Fig. 1c-d). After placing the chromosome associations in a phylogenetic context, these syntenies either occurred independently after radiation of each sub-

phyllinae (node B), which are based on comparative analyses. The abbreviations indicate proposed rearrangements. Fis, fission; $\mathrm{Fu}$, fusion; Inv, inversion. Abbreviations in parentheses correspond to chromosomal morphology or taxa analyzed by chromosome painting with MCA probes. A, acrocentric; B, biarmed (used to describe the linkage unit when the differences in morphology have not been confirmed with G-banding data); M, metacentric; SM, submetacentric; LAU, Lonchorhina aurita; LOC, Lophostoma occidentalis; GCR, Gardnerycteris crenulatum; TSA, Tonatia saurophila; GSO, Glossophaga soricina; ACU, Anoura cultrata; LCO, Lonchophylla concava. Letters beside a chromosome segment represent the ancestral short (p) or long (q) chromosome arm. Insert on bottomright shows MCA chromosome color key.

(For figure see next page.) 
a

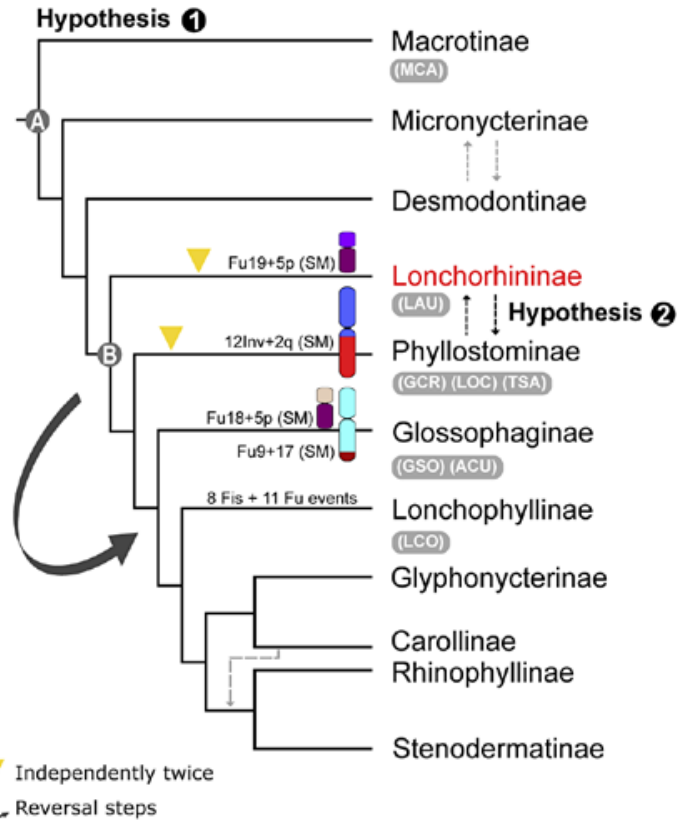

C Hypothesis 4

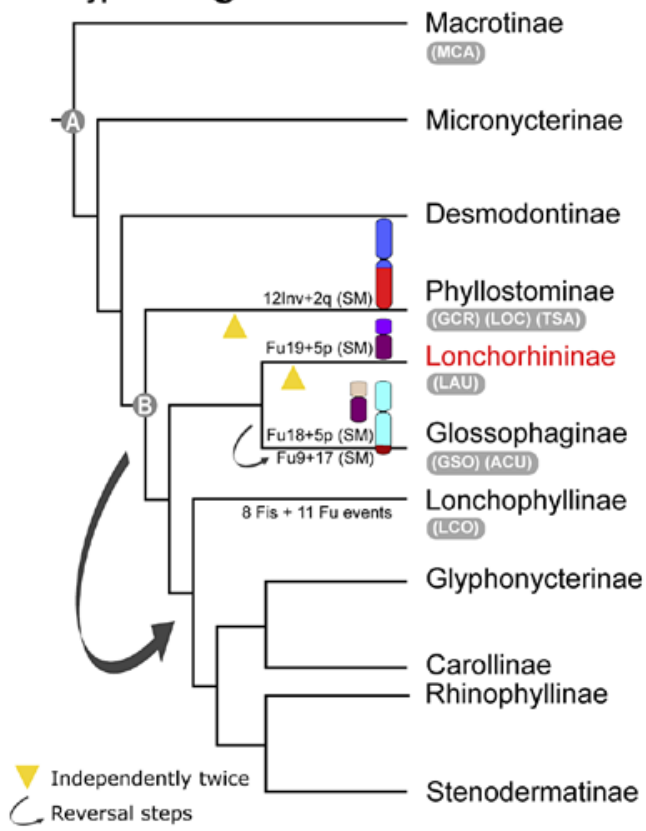

b
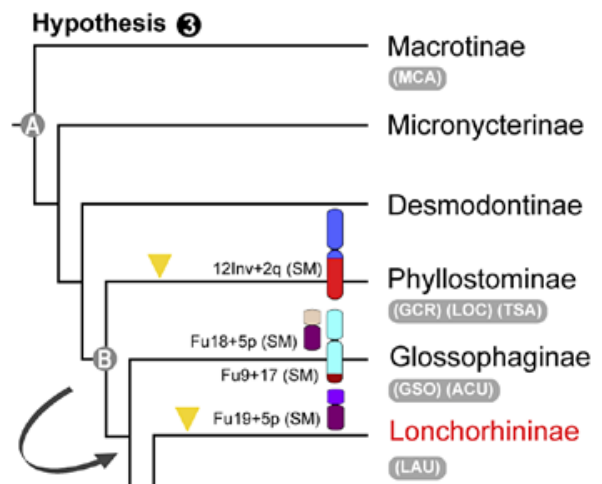

(LAU)

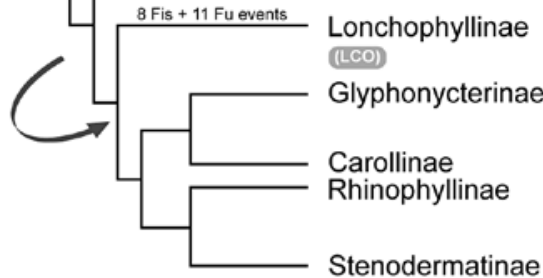

Independently twice

C. Reversal steps

d Hypothesis 6

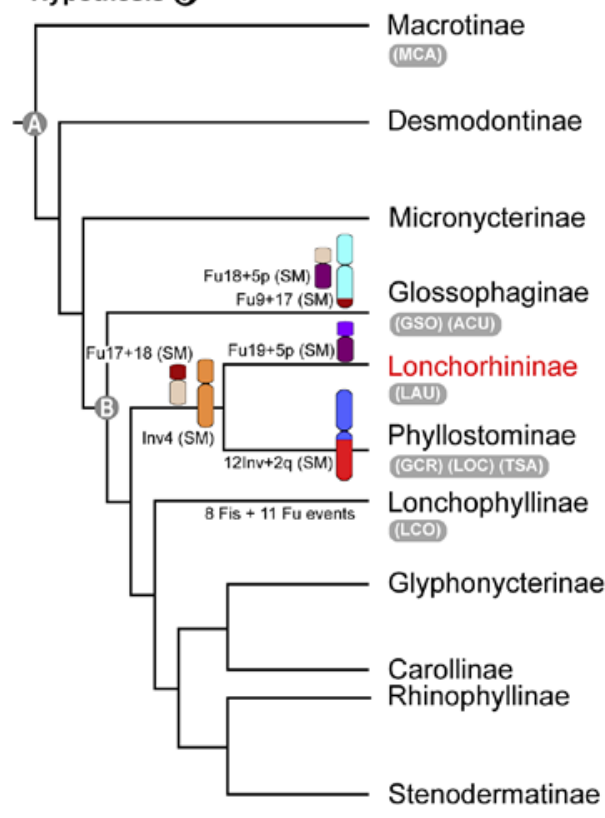

e

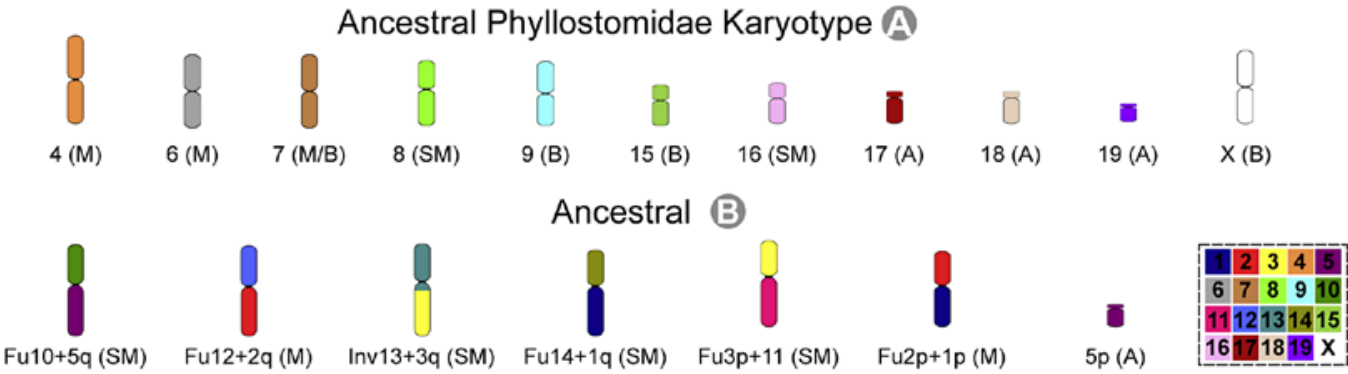

Chromosome Painting in Lonchorhina aurita (Chiroptera)
Cytogenet Genome Res 2021;161:569-577

DOI: $10.1159 / 000520969$ 
family (Fig. 3a-c) or as synapomorphies for a putative sister clade Lonchorhininae + Phyllostominae (Fig. 3d). Alternatively, though unlikely, these rearrangements occurred in the common ancestor after radiation of vampire bats (Desmodontinae) and were reversed to the original state after radiation of Phyllostominae and Lonchorhininae. The association of MCA $19+5 p$ until now was detected only in L. aurita (Table 1, Fig. 1d).

\section{Discussion}

Unlike other Lonchorhina species with relatively restricted occurrences, L. aurita has an extensive distribution in Central and South America [Mantilla-Meluk et al., 2019]. Despite its wide distributional range, cytogenetic studies of $L$. aurita from different regions (e.g., Brazil and Trinidad) revealed identical karyotypes with $2 \mathrm{n}=32$ and $\mathrm{FN}=60$, composed of 8 metacentric $(\mathrm{M}), 4$ submetacentric (SM), and 3 subtelocentric (ST) chromosomes [Baker, 1979; Barros et al., 2009]. The specimens investigated herein presented identical karyotypic features.

G-banding comparison between L. aurita and Trachops cirrhosus ( $2 \mathrm{n}=30, \mathrm{FN}=56$; Phyllostominae) was provided by Barros et al. [2009], using M. waterhousii Gbanded chromosome arms as reference and showed considerable divergence of the $L$. aurita karyotype from that of Macrotus but a high degree of similarities to that of $T$. cirrhosus. However, technique limitations prevented them to identify the rearrangements detected here. At least 3 conserved chromosome pairs between M. waterhousii and L. aurita were identified by Barros et al. [2009], all of which were present in our MCA/LAU mapping (MWA 6/7 = LAU $8=$ MCA 6; MWA 25/26 = LAU $9=$ MCA 15; and MWA 15/16 = LAU $11=$ MCA 7; the last 2 correspond to pairs LAU 15 and 10 in our analysis, respectively). Our chromosome painting analysis refined the identification of homology between the 2 genera and revealed several chromosome and chromosome arm homologies (Fig. 1).

The integration of our data with comparative maps of other phyllostomid species [Sotero-Caio et al., 2013, 2015] enabled us to identify shared chromosome associations between taxa (Table 1). Karyotypic conservation was observed among L. aurita and species from the genera Lophostoma and Gardnerycteris (Phyllostominae), as well as Glossophaga (Glossophaginae), which retained most of the syntenic associations found in L. aurita and differ by rearrangements involving chromosomes MCA 16-19. The different syntenies and homoplasy of chro- mosomes MCA 16-19 were highlighted in an evolutionary framework by Sotero-Caio et al. [2015].

On the other hand, L. aurita karyotype contrasts with the extreme chromosomal reshuffling already observed in Tonatia and Anoura (Phyllostominae and Glossophaginae, respectively). Comparative analysis has shown that 2 out of the 3 rearrangements proposed as Phyllostominae synapomorphies by Sotero-Caio et al. [2015], MCA 4inv and the association $17+18$, were also identified in the karyotype of L. aurita (Table 1). G-band comparisons confirmed the sharing of MCA 4inv with others Phyllostominae, as Lophostoma silvicola and Phyllostomus hastatus (Fig. 2); this rearrangement is also a Phyllostominae synapomorphy in Benathar et al. [2019]. Furthermore, the association MCA 19+5p, so far present only in L. aurita, suggests a probable synapomorphy for the genus Lonchorhina, pending confirmation of presence in other species.

\section{Alternative Karyotype Evolution Scenarios for $L$.}

\section{aurita in a Phylogenetic Perspective}

In an attempt to provide new insights into the chromosome changes that shaped the karyotype of Lonchorhininae, we plotted our chromosome data onto distinct phylogenetic hypotheses, corresponding to 5 alternative branching positions for Lonchorhininae (Fig. 3a-d; hypotheses 1-5). The genus Lonchorhina was originally included in the subfamily Phyllostominae based on morphological data [Wetterer et al., 2000]. However, since earlier molecular phylogenies [Baker et al., 2003a] supported its elevation to subfamily rank (Lonchorhininae; Fig. 3a; hypothesis 1), multiple alternative branching positions have been recovered in studies using distinct approaches, with variable levels of support [Rojas et al., 2011, 2016; Dumont et al., 2012; Dávalos et al., 2014; Baker et al., 2016; Amador et al., 2018]. In some phylogenies, Lonchorhininae appears as a lineage that diverged before nectarivorous bats but after Phyllostominae (Fig. 3a; hypothesis 2). These studies incorporated diverse datasets such as mtDNA including $c y t b$ [Rojas et al., 2011] and a combined analysis of molecular and morphological data [Dávalos et al., 2014]. Meanwhile, in other phylogenetic trees, such as in Baker et al. [2016], Lonchorhininae was recovered as an independent clade that diverged after Phyllostominae and Glossophaginae, but before Lonchophyllinae (Fig. 3b; hypothesis 3).

A sister relationship between Lonchorhininae and nectar-feeders of the subfamily Glossophaginae has been also one of the tree topology alternatives (Fig. 3c; hypothesis 4); these included analyses of mitochondrial COI incorporation with previous mtDNA data [Dumont et al., 2012], as 
well as larger mtDNA and nuclear gene samples [Rojas et al., 2016]. Amador et al. [2018], with focus on the chiropteran phylogeny, recovered a congruent Phyllostomidae tree in which Lonchorhininae appears as sister to Phyllostominae (Fig. 3d; hypothesis 5). Furthermore, the same clade was also observed in the well-supported maximum likelihood tree of Dávalos et al. [2014] and by Botero-Castro et al. [2018], which recovered a tree of entire mitochondrial genomes but including only 21 species of the 11 subfamilies recognized by Baker et al. [2016]. It is noteworthy that there is no robust support for the position of Lonchorhininae in any of the available phylogenies, regardless of methods and sampling effort made. In such controversial cases, using integrative taxonomic approaches with different data types collating independent observations in support of a major hypothesis is essential [Solari et al., 2019]. Current collections of data, especially echolocation and morphological, but also genetic, have shown that Lonchorhina displays unique patterns and trends relative to other phyllostomids, which complicates inferences of relationships based on comparative analyses [Wetterer et al., 2000; Dávalos et al., 2014; Gessinger et al., 2019, 2021].Thus, by estimating the branching position of Lonchorhina based on changes of chromosome architecture combined with all available phylogenetic hypotheses we hope to provide new information that might aid to the elucidation of relationships as new methods and approaches appear.

The simultaneous analysis of chromosomal changes along trees with alternative positions for the Lonchorhininae radiation demonstrates distinct number and order of chromosome change events, depending on branching order and position of Lonchorhininae on the Phyllostomidae tree. Assuming that shared syntenic associations between 2 taxa were also present in their common ancestor, several chromosomes and associations were consistently found in ancestral nodes and shown as ancestral Phyllostomidae characters (node A; Fig. 3e) or present in the common ancestor of phyllostomids that diverged after the radiation of vampire bats (node B; Fig. 3e). Similarly, some associations are unique to species within particular subfamilies and are shown in Figure 3 as synapomorphies on respective branches. These ancestral syntenies remained unchanged when compared to ancestral states proposed by Sotero-Caio et al. [2015] after the inclusion of the L. aurita dataset.

The major distinction across hypotheses is the emergence of the inversion MCA 4inv and fusion of MCA 17 +18 , which are shared only by L. aurita and Phyllostominae species. Analysis of the evolution of these associations, especially the inversion of chromosome homolo- gous to MCA 4, results in 3 informative scenarios in the discussion of systematics of Lonchorhininae, as follows: (1) in hypothesis 1 and 2 (Fig. 3a), these rearrangements might have occurred in the ancestral $\mathrm{B}$, were retained during divergence of Lonchorhininae and Phyllostominae, but then reversed back in the common ancestor of Glossophaginae and remaining Phyllostomid subfamilies (1 reversal), or alternatively arose independently twice (2 events for each chromosome rearrangement); (2) both hypothesis 3 and 4 (Fig. 3b-c) would require these characters to have appeared independently twice (in Phyllostominae and Lonchorhininae), or alternatively, emergence occurred in the ancestral B, followed by 2 independent reversals (in Glossophaginae and MCA of remaining phyllostomids); and (3) the most parsimonious evolutionary path of these derived chromosome states would be if Phyllostominae and Lonchorhininae were sister taxa (Fig. 3d), with the derived character states originating in their common ancestor. That would be the scenario with less steps ( 1 event for each chromosome change) and no character state reversal or independent origins.

Evolutionarily conserved chromosome associations shared between L. aurita and Phyllostominae might indicate common ancestry and support the phylogenetic hypothesis 5. However, Ferguson-Smith and Trifonov [2007] alert for de novo karyotypic changes (reuse of evolutionary breakpoints) and the need of careful breakpoint identification to prevent misleading phylogenetic interpretations and conclusions due to convergent events. This is especially true because homoplasy of chromosome characters can be less likely the effect of selection and more likely the result of underlying chromatin architecture of regions prone to breakage. Regional genomic landscapes can facilitate double-strand breaks, and some rearrangements are more prone to be fixed in populations, unless they confer selective disadvantages [Hedges and Deininger, 2007; Carbone et al., 2014]. It is important to keep in mind that chromosome painting was intensively applied to identified interchromosomal changes providing important information, and it is unable to accurately identify evolutionary breakpoint regions, but it has also been able to recover synapomorphic chromosome rearrangements in diverse mammalian families [Ferguson-Smith and Trifonov, 2007; Graphodatsky et al., 2012].

In the case of the present study, MCA $17+18$ reversal is a likely scenario, especially in phyllostomids, which seem to have recurrent fusion and fission of the smallest chromosomes [Sotero-Caio et al., 2015]. In comparison, the reversal of chromosome 4 inversion is less likely, especially if it is shown to use the same breakpoints, and due 
to constraints the rearrangement would impose in the fitness of heterozygous for the rearrangement. On the other hand, the inversion breakpoints might not be the same, and independent inversions of chromosome 4 remains a valid hypothesis. Even considering those scenarios, homology of rearrangements remains a valid hypothesis which, if confirmed, would imply a sister relationship between Phyllostominae and Lonchorhininae. In addition, the presence of 2 shared derived chromosome characters might be a further support for common ancestry of both subfamilies. Overall, to better understand the evolutionary process of the karyotypic changes, more robust molecular cytogenetic techniques, as BAC-FISH, and new "-omics" approaches using chromosome-level genome assemblies should be used to determine whether these chromosomes are homologous or homoplastic [Graphodatsky et al., 2012; Deakin et al., 2019].

In conclusion, our study showed that the L. aurita karyotype is derived when compared to that of $M$. californicus, but almost identical to other phyllostomid bats. We demonstrated alternative scenarios in the karyotype evolution of $L$. aurita in a phylogenetic context and, although we cannot exclude that these characters are a result of convergence, the associations MCA 4inv and $17+18$ represent shared derived characters that parsimoniously support a sister-clade Lonchorhininae + Phyllostominae. Karyotyping the remaining Lonchorhina species will be helpful to confirm chromosomal signatures in the genus and to reinforce the hypothesis of a monophyletic Lonchorhininae + Phyllostominae. Nonetheless, data provided here will allow inference of a chromosome painting phylogeny with representatives of all 11 subfamilies shortly. Finally, our work provides insights into the value of integrative studies and inclusion of chromosome data to refine hypotheses of relationships of controversial groups.

\section{Acknowledgement}

We thank Dr. Andrea Pedrosa-Harand and the Laboratório de Citogenética e Evolução Vegetal (UFPE, Brazil) for making the epifluorescence microscope available to us, and the Multi-users platform of Karyotyping-CARIOLAB/Departamento de Genética/CB at UFPE for use of its facilities funded by FACEPE (Fundação de Amparo a Ciência e Tecnologia do Estado de Pernambuco: APQ-0390-2.02/19). We are thankful for the sampling crews responsible for building the karyotype collection used in this study, especially Mário Ferreira (in memoriam), Cirlene Silva, Merilane Calixto, and Helen Barros. We also thank Fengtang Yang, Beiyuan $\mathrm{Fu}$, Bee L Ng who were responsible for preparing the MCA chromosome probes for CGS-C used in Sotero-Caio et al. [2013]. J.C.F. was recipient of MSc. scholarship from the Conselho Nacional de Desenvolvimento Científico e Tecnológico (CNPq-Brazil; Gradu- ate Program in Genetics - UFPE). C.G.S.-C. was supported by a postdoctoral fellowship (PNPD) from the Coordenação de Aperfeiçoamento de Pessoal de Nível Superior (CAPES - Brazil) during the development of this study.

\section{Statement of Ethics}

All procedures performed in this study involving animals followed guidelines established by Animal Care and Use guidelines of ICMBio (Instituto Chico Mendes de Conservação da Biodiversidade) and using the collecting permit number $(12,264-1)$ by the Instituto Brasileiro do Meio Ambiente e dos Recursos Naturais Renováveis (IBAMA).

\section{Conflict of Interest Statement}

The authors have no conflicts of interest to declare.

\section{Funding Sources}

J.C.F. was supported with a MSc. scholarship from CNPq-Brazil, and C.G.S.-C. was supported by a Postdoctoral scholarship from CAPES-Brazil.

\section{Author Contributions}

C.G.S.-C. and N.S. coordinated the study. N.S. and C.G.S.-C. were part of the crew that collected the specimens. J.C.F. and D.P.B. performed the experiments. Data analysis, table and figures preparation was performed by J.C.F. and C.G.S.-C. The first draft was written by J.C.F. and later versions by J.C.F. and C.G.S.-C. All authors read, revised, and approved the final version.

\section{Data Availability Statement}

All data generated or analyzed during this study are included in this article. Further enquiries can be directed to the corresponding author.

References

Amador LI, Arévalo RLM, Almeida FC, Catalano SA, Giannini NP. Bat systematics in the light of unconstrained analyses of a comprehensive molecular supermatrix. J Mammal Evol. 2018;25:37-70.

Baker HDR. The Family in State and Society. In: Baker RJ, Jones JK, Carter DC, editors. Biology of bats of the New World family Phyllostomatidae Part III. Special Publications Mus Texas Tech Univ; 1979. 16. p. 107-35.

Baker RJ, Bickham JW. Karyotypic evolution in bats: Evidence of extensive and conservative chromosomal evolution in closely related taxa. Systematic Biology. 1980;29(3):239-53. 
Baker RJ, Hoofer SR, Porter CA, Van Den Bussche RA. Diversification among New World leaf-nosed bats: an evolutionary hypothesis and classification inferred from digenomic congruence of DNA sequence. Occas Papers Mus Texas Tech Univ. 2003a;230:1-32.

Baker RJ, Hamilton MJ, Parish DA. Preparations of mammalian karyotypes under field conditions. Occas Papers Mus Texas Tech Univ. 2003b;228:1-8.

Baker RJ, Solari S, Cirranello A, Simmons NB. Higher level classification of phyllostomid bats with a summary of DNA synapomorphies. Acta Chiropterologica. 2016;18(1):138.

Barros HMDR, Sotero-Caio CG, Santos N, Souza MJ. Comparative cytogenetic analysis between Lonchorhina aurita and Trachops cirrhosus (Chiroptera, Phyllostomidae). Genet Mol Biol. 2009;32:748-52.

Benathar TCM, Nagamachi CY, Rodrigues LRR, O'Brien PCM, Ferguson-Smith MA, Yang F, et al. Karyotype, evolution and phylogenetic reconstruction in Micronycterinae bats with implications for the ancestral karyotype of Phyllostomidae. BMC Evol Biol. 2019;19:98.

Botero-Castro F, Tilak M, Justy F, Catzeflis F, Delsuc F, Douzery EJP. In Cold Blood: Compositional Bias and Positive Selection Drive the High Evolutionary Rate of Vampire Bats Mitochondrial Genomes. Genome Biol Evol. 2018;10:2218-39.

Carbone L, Harris RA, Gnerre S, Veeramah KR, Lorente-Galdos B, Huddleston J, et al. Gibbon genome and the fast karyotype evolution of small apes. Nature. 2014;513:195-201.

Dávalos LM, Velazco PM, Warsi OM, Smits PD, Simmons NB. Integrating incomplete fossils by isolating conflicting signal in saturated and non-independent morphological characters. Syst Biol. 2014;63:582-600.

Deakin JE, Potter S, O’Neill R, Ruiz-Herrera A, Cioffi MB, Eldridge MDB, et al. Chromosomics: Bridging the Gap between Genomes and Chromosomes. Genes (Basel). 2019;10: 627.

Dumont ER, Dávalos LM, Goldberg A, Santana SE, Rex K, Voigt CC. Morphological innovation, diversification and invasion of a new adaptive zone. Proc Biol Sci. 2012;279:1797805
Ferguson-Smith MA, Trifonov V. Mammalian karyotype evolution. Nat Rev Genet. 2007;8: 950-62.

Gessinger G, Gonzalez-Terrazas TP, Page RA, Jung K, Tschapka M. Unusual echolocation behaviour of the common sword-nosed bat Lonchorhina aurita: an adaptation to aerial insectivory in a phyllostomid bat? R Soc Open Sci. 2019;6:182165

Gessinger G, Page R, Wilfert L, Surlykke A, Brinkløv S, Tschapka M. Phylogenetic Patterns in Mouth Posture and Echolocation Emission Behavior of Phyllostomid Bats. Front Ecol Evol. 2021;9:630481.

Graphodatsky A, Ferguson-Smith MA, Stanyon R. A short introduction to cytogenetic studies in mammals with reference to the present volume. Cytogenet Genome Res. 2012;137:8396.

Hedges DJ, Deininger PL. Inviting instability: Transposable elements, double-strand breaks, and the maintenance of genome integrity. Mutat Res. 2007;616:46-59.

Mantilla-Meluk H, Perez-Amaya N, Velazco PM. Morphometric variation of the genus Lonchorhina (Chiroptera, Lonchorhininae), with noteworthy comments on taxonomy and distributional range extensions. In: Bradley RD, Genoways HH, Schmidly DJ, Bradley LC, editors. From field to laboratory: a memorial volume in honor of Robert J. Baker. Special Publications Mus Texas Tech Univ; 2019. 71. p. 149-68.

Pieczarka JC, Nagamachi CY, O’Brien PC, Yang F, Rens W, Barros RMS, et al. Reciprocal chromosome painting between two South American bats: Carollia brevicauda and Phyllostomus hastatus (Phyllostomidae, Chiroptera). Chromosom Res. 2005;13:339-47.

Ribas TFA, Rodrigues LRR, Nagamachi CY, Gomes AJB, Rissino JD, O’Brien PCM, et al. Phylogenetic reconstruction by cross-species chromosome painting and G-banding in four species of Phyllostomini tribe (Chiroptera, Phyllostomidae) in the Brazilian Amazon: An independent evidence for monophyly. PLoS One. 2015; 10:e0122845.

Rojas D, Vale A, Ferrero V, Navarro L. When did plants become important to leaf-nosed bats? Diversification of feeding habits in the family Phyllostomidae. Mol Ecol. 2011;20:2217-28.
Rojas D, Warsi OM, Dávalos LM. Bats (Chiroptera: Noctilionoidea) challenge a recent origin of extant Neotropical diversity. Syst Biol. 2016;65:432-48.

Rokas A, Holland PW. Rare genomic changes as a tool for phylogenetics. Trends Ecol Evol. 2000;15:454-9.

Seabright M. A rapid banding technique for human chromosomes. Lancet. 1971;2:971-2.

Simmons NB, Cirranello AL. Bat Species of the World: A Taxonomic and Geographic Database; 2020. Available from: https://batnames. org/.

Solari S, Sotero-Caio CG, Baker RJ. Advances in systematics of bats: towards a consensus on species delimitation and classifications through integrative taxonomy. J Mammal. 2019;100(3):838-51.

Sotero-Caio CG, Volleth M, Gollahon LS, Fu B, Cheng W, Ng BL, et al. Chromosomal evolution among leaf-nosed nectarivorous bats-evidence from cross-species chromosome painting (Phyllostomidae, Chiroptera). BMC Evol Biol. 2013;13:276.

Sotero-Caio CG, Volleth M, Hoffmann FG, Scott L, Wichman HA, Yang F, et al. Integration of molecular cytogenetics, dated molecular phylogeny, and model-based predictions to understand the extreme chromosome reorganization in the Neotropical genus Tonatia (Chiroptera: Phyllostomidae). BMC Evol Biol. 2015; $15: 220$.

Sotero-Caio CG, Baker RJ, Volleth M. Chromosomal Evolution in Chiroptera. Genes (Basel). 2017;8:272.

Volleth M, Heller KG, Pfeiffer RA, Hameister H. A comparative ZOO-FISH analysis in bats elucidates the phylogenetic relationships between Megachiroptera and five microchiropteran families. Chromosome Res. 2002;10: 477-97.

Volleth M, Son NT, Wu Y, Li Y, Yu W, Lin LK, et al. Comparative chromosomal studies in Rhinolophus formosae and R. luctus from China and Vietnam: Elevation of R. 1. lanosus to species rank. Acta Chiropt. 2017;19:41-50.

Wetterer AL, Rockman MV, Simmons NB. Phylogeny of phyllostomid bats (Mammalia: Chiroptera): data from diverse morphological systems, sex chromosomes, and restriction sites. B Am Mus Nat Hist. 2000;248:1-200. 